\title{
COMPETITIVIDADE DAS DESTINAÇÕES TURISTICAS A LONGA DISTÂNCIA Realidade e Perspectivas de Desenvolvimento na América do Sul
}

\author{
Mário Carlos Beni
}

\begin{abstract}
RESUMO: Tratando da competitividade das destinações turisticas a longa distância, discute o turismo e a mobilização de capitais, o interesse do Estado em promover o turismo e o papel do setor privado no mesmo. Neste último tópico aborda a necessidade de desenvolvimento de rotas aéreas bem planejadas e estruturadas no Atlântico Sul, ressaltando a importância de roteiros integrados.
\end{abstract}

PALAVRAS-CIIAVE: Destinações turisticasa longa distância; competitividade; rotas aéreas; América do Sul.

ABSTRACT: The text discusses tourism and the capitals flow focusing on the competitivity of long distance tourist destinations, the interest of the Government in tourism promotion and the role

Within this last issue, the necessity of developing well planned air routes and infrastructure in the Southern Atlantic region is proposed, stressing the importance of integrated schedules.

KEY WORDS: Long distance tourist destinations; competitivity; air routes; South America.

Iniciạmente, é importante fixar três pontos de grande importância:

a) contextualizar o setor de Turismo como sendo um dos maiores na mobilização de capitais, e compartilhar nossavisão otimista do seu futuro a longo prazo. Uma questão fundamental para investimentos;

1 Livre Docente e Professor Associado do Curso de Turismo da Escola de Comunicações e Artes da Universidade de São Paulo.

End. para corresp.: ECA-USP - Departamento de Relações Públicas, Propaganda e Turismo Cidade Universitária "Armando de Salles Oliveira" - Av. Prof. Lúcio Martins Rodrigues, 443, bloco B - Butantã - 05508-900 - São Paulo - SP - Brasil. 
b) oferecer sugestões sobre porquê os governos deveriam dar prioridade ao estímulo dos investimentos neste setor, e indicar o tipo de política a ser seguida objetivando o êxito dos programas;

c) mostrar o que as pessoas do setor precisam fazer para poder desempenhar seus respectivos papéis no compromisso existenteentre os setores público e privado, e para gerar investimentos. Inicia-se pela Economia.

\section{TURISMO E MOBILIZAÇÃO DE CAPITAIS}

Na ótica da prestação de serviços, o turismo é uma atividade fragmentada - transportes, hotelaria, alimentação, atrações e serviços receptivos. Cada setor economicamente significativo, mas nenhum com a influência política de indústrias, como a automobilística, têxtil ou agrícola. O turismo não é visto como uma atividadeeconômica de base estrutural c impulsionadora do desenvolvimento. Veja-se o seguinte:

a) dados turísticos não aparecem nos quadros estatísticos do país, que servem de fundamento para as prioridades nas decisões econômicas, políticas e sociais do governo;

b) raramente o turismo marca presença nas agendas das grandes personalidades, que definem os rumos do país: Ministros da Fazenda, Ministros dos Transportes etc.;

c) com muita freqüência, amplas políticas públicas que afetam investimentos, infra-estrutura, empregos c fatores semelhantes simplesmente não refletem de maneira adequada o impacto do turismo.

Isso está errado, uma vez que o efeito econômico das divisas trazidas pelos turistas sobre o consumo, o comércio, os investimentos, a cobrança de impostos e os empregos é extremamente significativo.

Segundo as previsões mais recentes da World Travel \& Tourism Council (WTTC), em termos globais, em 1993, o turismo respondeu por cerca de $10 \%$ do PIB mundial, o equivalente a US\$3,5 trilhões; criou 1 em 15 empregos na cconomia, correspondendo a $6,6 \%$ da oferta total de empregos. Isso torna o turismo a maior indústria do mundo. Maior do que a indústria eletrônica do Japão, as de aço e de automóveis dos Estados Unidos c a agrícola da Europa.

O mercado de Turismo se renova a cada ano e aí reside o seu verdadeiro crescimento. O turismo de negócios, por exemplo, continuará acompanhando a expansão comercial. A clientela jovem assim como a das pessoas da terceira idade está aumentando. Há também um número maior de famílias com dois empregos que tiram duas férias. O mercado daqueles que se aposentam cedo, com melhores condições de saúde e poder aquisitivo, ć particularmente interessante.

Novos produtos como o turismo de aventura, o turismorural e o turismo ecológico estão conseguindo grande penetração nos mercados tradicionais e, neste sentido, a América Latina descortina-se como destacado mercado potencial.

Acredita-se que, à medida que as economias ganharem nova vida, o livre comércio retomar o rumo com um circuito estruturado, sistêmico e completo, c os mercados regionais comuns se concretizarem como a CEE e o Mercosul, no Brasil voltar-se-á a prosperar.

Vê-se, portanto, um crescimento global da atividade turística em alguns percentuais acima da economia, geralmente de 4 a $5 \%$. Uma das regiões promissoras será a Ásia, onde se espera um crescimento entre 7 a $10 \%$, e que será responsável por cerca de metade do turismo internacional em 2005. Basta considerar o crescimento da economia chinesa com Hongcong, Macau c Formosa numa associação econômica, a duplicação do turismo japonês receptivo e emissivo na virada do século, a Coréia e a Indonésia, para ter-se uma idéia da força dessa parte do globo.

É importante salientar que o crescimento do Turismo na Ásia deve-se, em grande parte, ao Japão, não só pelo seu destacado desenvolvimento econômico, mas também, c principalmentc, pelos investimentos no setor de Turismo em todo o Sudeste Asiático, que teve seu impulso inicial no início da década de 70 .

O Japão foi pioneiro nos investimentos de infra-estrutura turística no país, criando uma das mais notáveis redes hoteleiras e de serviços turísticos, investindo maciçamente em parceria com ospaíses da região, instalando uma efetiva infra-estrutura de lazer e entretenimento com rotciro estruturado e articulado, integrando com coerência e competência tecnológica os principais pólos de destinação turística do Sudeste Asiático. Para consolidar esse programa, o Japão conseguiu um feito extraordinário até hoje não superado por nenhuma outra iniciativa no âmbito internacional: através de uma competente e estruturada campanha promocional, estratégia de marketing, gestão institucional c empresarial aliadas a consistentes diretrizes políticas, abriu para o Ocidente, através da Japan Air Lines, a Rota Polar Ártica, com escala em Anchorage (Alasca), conseguindo estabelecer pioneiro tráfego aéreo, que acabou por "abocanhar" surpreendentemente, já na segunda metade da década de 70 , quase $20 \%$ do tráfego de turismo no Atlântico Norte.

Ncsta época, num esforço mercadológico sem precedentes, lançaram um pacote turístico de impressionante ousadia. "Vá à Europa via Japão c aproveitc para conhecer o Sudeste Asiático", tudo isso pagando apenas mais 
$25 \%$ da tarifa normal da Europa via Atlântico Norte.

Opacote turístico envolvia Nova York/Tóquio,com escala em Anchorage (Alasca); Tóquio/Osaka pela "New Tokaido Line" (o trem-bala); Osaka/ Hongcong; Hongcong/Manila (Filipinas); Manila/Bangcoc (Tailândia); Bangcoc/Karachi (Paquistão); Karachi/Atenas (Grécia); Atenas/Roma (Itália).

A promoção permaneccu por longo tempo explorando o exótico e as promessas de aventura da oferta turística do Sudeste Asiático, tão a gosto do consumidor americano. Tempo necessário para consolidar mercadologicamente a Rota Polar, hoje usada por empresas aéreas americanas e européias. A campanha teve êxito total e, já em 1978, o Japão viu-se pressionado a construir Narita, o modernoaeroporto internacional de Tóquio para suportar o impressionante tráfego aéreo internacional que se estabelecera.

Tem-se visto poucos pesquisadores e analistas de turismo citarem esta iniciativa do Japão nos estudos do mercado de viagens, muito embora seja o mais significativo exemplo na conquista e competitividade das destinações turísticas a longa distância.

É importante citar que, de acordo com as previsões feitas neste artigo com base nos dados da OMT, a entrada de turistas estrangeiros na América do Norte cresceu: em 1993 seria de 66.246 milhões. No Caribe, o aumento previsto do turismo internacional para 1993 é de 5,5\%, ou seja, 12.246 milhões. Na América do Sul, o turismo internacional cresceu 5,49\%, que corresponde, na previsão feita para 1993, a 9.998 milhões². $^{2}$.

De um modo geral, consoante as estatísticas da OMT, $80 \%$ dos fluxos receptivos internacionais e cerca de $70 \%$ dos ingressos de divisas concentram-se na Europa e na América do Norte. O restante está distribuído entre as outras regiões do mundo. A África fica com $2,82 \%$ das chegadas e $2,28 \%$ dos ingressos; a Ásia e a Oceania com 10,75\% e 13,6\% respectivamente; e o Oriente Médio com 2,32\% e 3,5\%, respectivamente. A América Latina e o Caribe registram aproximadamente $7 \%$ do tráfego receptivo mundial e $11 \%$ dos ingressos de divisas.

A OMT prevê, para 1995, a chegada de cerca de 130 milhões de turistas nas Américas, com uma receita estimada de US\$ 95 bilhões, procedente do turismo internacional. As previsões até o ano de 2005 sugerem que:

a) a contribuição da indústria à produção mundial aumentará $100 \%$;

b) o número de empregos gerados aumentará $33 \%$, representando um emprego a cada 10 segundos;

2 Ver integra dos dados no Anexo - A Realidade do Tráfego Turistico Receptivo Global. c) o investimento de capital dará um salto de $80 \%$, passando a US\$750 milhões por ano.

Esses números elevados conduzem ao segundo ponto: o interesse do Estado em promover o setor de Turismo.

\section{INTERESSE DO ESTADO EM PROMOVER O TURISMO}

Considerando o impacto máximo na produção, nos empregos, no capital e em outros indicadores econômicos, acredita-se que o reconhecimento, por parte dos governos, será cada vez maior com relação ao papel desempenhado pelo turismo, e o setor ganhará prioridade para o desenvolvimento estratégico.

Um número crescente de governos já começou a trabalhar nesse sentido: Austrália, Argentina, Brasil, China e Japão possuem novas políticas. O secretário do Comércio dos Estados Unidos, chamando a atenção para o superávit comercial de US\$16 milhões, prometeu estudar imediatamente 0 caso do setor de Turismo. A Comunidade Européia, meticulosamente e devagar, está começando a acordar para a erosão contínua da sua fatia de mercado.

Há mais a acrescentar do que os números absolutos:

a) cxiste o estímulo ao crescimento e à criação de empregos, sendo esta a principal preocupação do governo hoje em todo o mundo;

b) existem moedas estrangeiras e valor de exportação;

c) existe o fato de que as divisas geradas pelo Turismo são disseminadas rapidamente pela economia, estimulando pequenos negócios, atividades bancárias, telecomunicações, construções etc.;

d) existe o impacto dinâmico nas economias em transição na Europa do Leste por exemplo, ou nos Estados em desenvolvimento. Nestes, o turismo pode ser a única forma de vantagem comparativa, e também o catalisador de infra-estrutura ou de projetos de desenvolvimento regional, os quais não ocorreriam se fosse de outra forma.

Para aproveitar essas características e criar o clima certo para os investimentos, precisa-se de políticas e programas imaginativos. Sim, de políticas e programas destinados aos investidores. Principalmente num mundo onde é cada vez maior a concorrência para atrair turistas. Para isso 
há inúmeras possibilidades: áreas empresariais, créditos para exportação, garantias de empréstimos, concessões de impostos, isençãofiscal temporária c outros fatores.

A boa receptividade, entretanto, será em casos específicos. O cerne da questão é que os governos deveriam tratar o setor de Turismo plenamente como um produto de exportação; deveriam garantir livre movimento de mãode-obra e do lucro obtido com a venda do capital fixo; deveriam proporcionar apoio equivalente ao dado às outras indústrias prioritárias de desenvolvimento. Sim, políticas destinadas à promoção.

Un número crescente de países tem aumentado seu apoio ao Turismo, mas a maioria não conseguever ou as ligações econômicas ou como pode agir em face das condições orçamentárias gerais. É importante que esses países se preocupem com as conseqüências do fracasso, a fim de proporcionar apoio adequado na balança comercial geral. Também é importanteque os governos pensem em termos de parcerias entre os setores privado e público para estimular a promoção. A Austrália constitui excelente exemplo, com cerca de US\$70 milhões de fundos do governo, que ultrapassaram US\$ 100 milhões com as contribuições do setor privado.

Contudo, as políticas que realmente contam são aquelas que estimulam o comportamento eficiente do mercado e dos produtos viáveis, ou seja:

a) liberalização do transporte aéreo;

b) manutenção da lei e da ordem, oferecendo maior segurança à integridade dos turistas;

c) implantação e consolidação da infra-estrutura turística com compatibilização dos meios de transportes, dos equipamentos receptivos, meios de hospedagem e serviços. As tarifas de competição do mercado internacional, modernização nas instalações e operacionalização dos aeroportos e, basicamente, os sistemas de controle de tráfego aéreo via satélite para reduzir atrasos dispendiosos;

d) automatização do controle de fronteiras e dos procedimentos de entrada para os turistas, e eliminação de processos burocráticos frustrantes;

e) estímulo à responsabilidade sobre o meio ambiente através de práticas saudáveis por parte das empresas e não por meio de regulamentos que elevam os custos;

f) estabelecimento de justa cobrança de impostos para o setor de Turismo, a fim de garantir a qualidade do produto, do atendimento e dos serviços, em vez de explorá-lo, o que acaba por reduzir a demanda em cada estágio da cadeia turística - alojamentos hoteleiros, melhorias aeroportuárias, segurança e processos de inspeção nas instalações turístico-recreativas.

Acertar essas seis diretrizes está entre as medidas mais importantes que os governos podem tomar para atrair investimentos numa economia de mercado. Isso leva ao terceiro e último ponto: o papel cada vez mais relevante do setor privado

\section{O PAPEL DO SETOR PRIVADO}

Para sustentar o investimento, tem-se de ser lucrativo. Para tanto, é preciso reestruturar-se radicalmente para responder à globalização, privatização, computadorização, diversificação, qualidade e consolidação do produto.

Ao mesmotempo, está-se na chamada década da qualidade e do valor. Os custos de insumo estão aumentando. A concorrência mantém pressão sobre os rendimentos. Turistas bem-informados e conscientes dos seus orçamentos exigem um preço justo pelos serviços contratados.

Deve-se aprimorar continuamente técnicas de gerenciamento, a fim de aumentar a produtividade, qualidade e competitividade, e melhorar técnicas de treinamentos e programas. Em suma, precisa-se:

a) consolidar a base de rendimentos, manter os custos baixos, manter o níve da qualidade alto e intensificar o serviço de atendimento ao cliente;

b) organizar-se para garantir que o crescimento seja compatível com o meio ambiente.

O meio ambiente é a matéria-prima do turismo e, à medida que os ecossistemas pós-ECO/92 começam a ser traduzidos em normas e regulamentos, deve-se liderar em vez de ser liderado. O turismo deverá perseverar na correta utilização e preservação ambiental, fonte quase inesgotável de recursos e fruição de scus consumidores.

Efeitos adversos do meio ambiente devem ser reduzidos com uma prática gerencial inteligente - avaliações de impacto e auditorias, treinamento de pessoal e conscientização do cliente.

O desenvolvimento do tráfego turístico internacional na América do Sul, principalmente no que tange aos países do Cone Sul e do Pacto Andino a exemplo do que ocorreu na década de 70 com o Sudeste Asiático, que já foi 
abordado, está diretamente ancorado na implantação, consolidação, atualização e regionalização das rotas aéreas de longa distância

A competitividade das atraentes tarifas do Atlântico Norte são sustentadas por consolidado tráfego aéreo de passageiros e cargas, ainda concentrando a maior fatia do mercado mundial de turismo. Para concorrer com essa área, atraindo significativo contingente de turistas, seria preciso adequar a infra-estrutura de alojamentos e serviços, compatibilizando-a aos níveis internacionais, e ampliá-la para atender a enorme e diversificada oferta natural de Turismo no próprio continente sul-americano.

É axioma que sem deslocamento não existe Turismoe, sem rotas aéreas bem-planejadas e estruturadas no Atlântico Sul, o Turismo não poderá se desenvolver. Ressalta-se, novamente, a prioridade de implantação, consolidação, atualização e regionalização das rotas aéreas de longa distância na América do Sul contendo, em seu próprio bojo, a competitividade tarifária aliada à oferta de recursos e atrativos turísticos, equipamentos e serviços.

Destaca-se no Atlântico Sul uma rota recém-implantada pela Viação Aérea Rio Grandense (VARIG), que parte de São Paulo (via Johannesburgo, África do Sul), indo para Johannesburgo, Bangcoc e Hongcong. Essa rota é extremamente importante no tráfego com o Sudeste Asiático, não só pelas perspectivas de desenvolvimento, mas também porque a região dos "trigres asiáticos" tende a ser cada vez mais competitiva e expansionista em produção e comércio.

Hoje, a redução da milhagem aérea é sempre procurada e explica os acordos operacionais que se estabelecem entre as empresas aéreas. No exemplo citado, por acordo com a South African Airlines (SAS), a VARIG transporta, deHongcong a Bangcoc, passageiros e cargas do Sudeste Asiático para Johannesburgo, e, em troca, ofereceu à SAS a rota Johannesburgo/Los Angeles.

Essa rota é sustentada por expressivo transporte de cargas. Tratam-se de mercadorias da Coréia, de Formosa e de Hongcong que a VARIG embarca em contêineres, desembarcando-os em Ciudad del Leste (Paraguai), centro abastecedor de parcela substancial do consumo brasileiro. Observa-se, portanto, que esta rota aérea tem de ser ampliada, através de significativo esforço de marketing.

No Pacífico Norte, a manutenção e consolidação das rotas aéreas via Los Angeles são exploradas hoje pela VARIG que segue até Tóquio, e pela VASP com destino a Seoul(Coréia).Esta última, ao contrário da expectativa, vem desafiando aqueles que a julgavam de difícil sustentação e afirmandose como rota viável, em face da competitividade de preço, antevendo-se a sua consolidação com ampliação prevista para 1994, de uma linha para Beijin
(Pequim, China). Será uma oportunidade de mercado para escoamento de cargas e passageiros com destino à América do Sul pelo Pacífico.

No Pacífico Sul, duas rotas, embora já implantadas, precisam ser melhor estruturadas e mais ativas, no sentido de conquistar novos mercados.

A primeira é da Lan Chile, que hoje tem a participação do Grupo Iberia, e que poderá ter um maior aporte técnico e financeiro para sua consolidação Essa rota faz Santiago, Ilha da Páscoa, Papeete (Taiti), e, eventualmente, poderia ser estendida para a Polinésia, a Austrália e o Sudeste Asiático, restaurando no ar a aventura épica do Kon Tiki, de Thor Heyerdahl, pelo mar.

Ainda mais ao sul, já existe uma rota com freqüência semanal, que parece depender de implantação e de significativa melhoria na infraestrutura aeroportuária. É operada pela Aerolineas Argentinas, agora integrante do Grupo lberia. Essa rota, mantida em precárias condições técnicas, que se pode chamar de Polar Antártica, integra Buenos Aires, Ushuaia e Rios Galegos (Patagônia), a Melbourne (Austrália); e, eventualmente, poderia ser ampliada para atender Wellington (Nova Zelândia), em direção à Austrália e Sudeste Asiático.

Segundo informações de colegas argentinos, essa rota deveria definirse técnica e operacionalmente entre Ushuaia, que já apresenta condições turísticas, e Rios Galegos, e desenvolver uma ou outra das destinações. Essa rota, eventualmente, utilizaria a base de Mac Murdok (PóloSul), como apoio técnico nos vôos para a Nova Zelândia.

\section{CONSIDERAÇÕES FINAIS}

As rotas acima mencionadas, se analisadas separadamente c como destinações turísticas e transporte de cargas, dificilmente se sustentariam. Prova disso é a freqüência de vôo para a Austrália, uma vez por semana, invariavelmente cancelada.

O que é preciso para consolidar essas rotas? Novamente, recorre-se ao exemplo do Japão. Necessita-se, acima de tudo de rotas coerentes.

Na América do Sul, por exemplo, o deslocamento pela área territorial do Brasil e da Argentina equivale a uma milhagem por toda a Comunidade Européia, da maneira como é feita atualmente, onde os turistas têm de voltar várias vezes aos mesmos aeroportos para seguir em direções diferentes, porque não há ligações nem interconexões. Istu encarece muito os pacotes turísticos.

Convém lembrar que o Cone Sul, além de se encontrar desfavorecido pela grande distância em relação aos pólos emissores tradicionais de turistas, sofre ainda os efeitos do cartel das empresas aéreas, que mantém elevadas as tarifas do Atlântico Sul, ao contrário das praticadas no Atlântico Norte, onde 
essa política acirrou a concorrência entre as companhias aérease, conseqüentemente, promoveu a redução das tarifas.

Há de se ressaltar também que um dos instrumentos principais de massificação do tráfego turístico aéreo são os vôos fretados (charters), com tarifas promocionais em pacotesespeciais, de grande sucessomercadológico. Estes, no caso específico do Brasil, embora estimulados pelo órgão nacional de Turismo, inviabilizam-se em face das elevadíssimas taxas operacionais praticadas pelos serviços aereoportuários do país e cobradas às empresas de transporte aéreo estrangeiras ${ }^{3}$.

Por isso tudo é que são urgentes e indispensáveis algumas diretrizes, como incentivar a conscientização do que seja regional, regionalização, intercontinentalidade; buscar e premiar contratos de parceria; motivar os governos para integrarem-se - aexemplo do Mercosul; implantar rotas aéreas sem ziguezagues e retornos. Enfim, roteiros integrados em que não se repetem idas e voltas, como no exemplo do Japão e Sudeste Asiático. Até porque, num futuro não muito distante, ver-se-á a formação de macroempresas aéreas, com a fusão das atuais, cobrindo todo o espaço aéreo do planeta.

Isto tudo compete a cada um de nós, que atuamos no setor de Turismo, propalar e incentivar discussões, motivando e demonstrando a eficiência e a eficácia desse tipo de realização evidente por si mesma em sua lógica e coerência. Quando se atingir a consciência de que não se pode vender a Argentina ou o Brasil isoladamente, mas todo o Cone Sul, o caminho estará pronto para seguir rumo à verdadeira integração regional. Mesmo porque, como exemplo, os Pampas Gaúchos avançam fronteiras binacionais.

\section{BIBLIOGRAFIA}

ABAV - Associação Brasileira de Agentes de Viagens. 1993. O que as autoridades, os governos e os parlamentares devem saber sobre turismo. Turismo é indústria. São Paulo, 2 out.

BRASIL. Ministério da Aeronáutica. Departamento de Aviação Civil. 1992. Anuário do Transporte Aéreo. Dados Estatisticos (Brasil - 1992). Brasilia.

LIPMAN, Geoffrey. Generating investment in the world's largest industry. Belgium: WTTC. LICKORISH, Leonard. Scenarios for the development of tourism, to and from Europe. U.K. JAFARI, Jafar. Anchoring tourism development in a global economy. USA: Academy for the Study of Tourism.

\section{ANEXO}

A Realidade do Tráfego Turístico Receptivo Global

As mais recentes pesquisas fundamentadas nas tabelas estatísticas da Organização Mundial do Turismo (OMT), dão conta de um ingresso de turistas procedentes do Exterior, numa projeção feita para 1993 (com base nos dados de 1989), conforme abaixo especificado.

\section{DISCRIMINAÇÃo}

EM MILHÕES

Mundo 494.473

África...

18.743

Américas

97.251

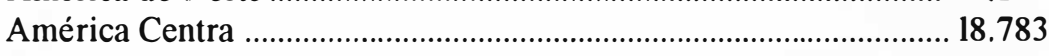

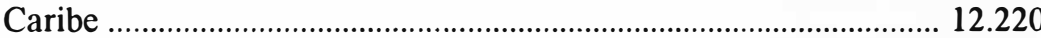

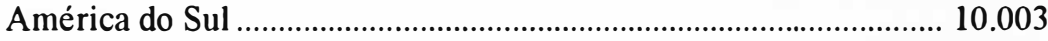

Ásia e Oceania ............................................................................... 72.533

Sudeste Asiático e Oceania .............................................................. 54.726

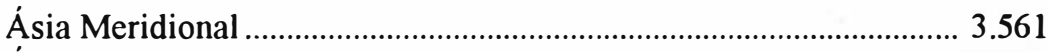

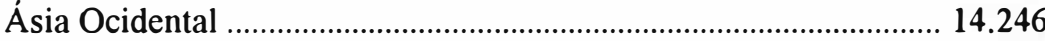

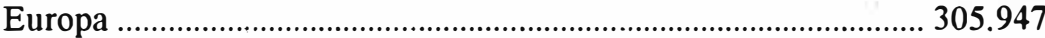

Também para o ano de 1993, as previsões estatísticas detalhadas em milhões, conforme o ano-base de 1988, são as relacionadas a seguir.

\section{DISCRIMINAÇÃO}

EM MILHÕES

Caribe

12.246

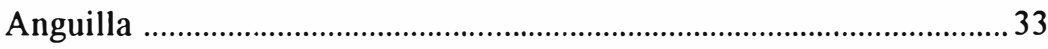

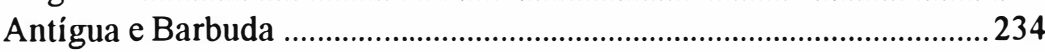

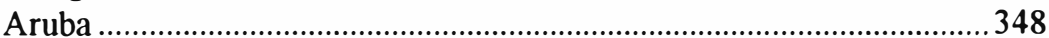

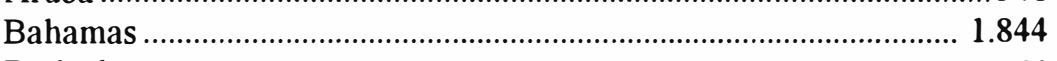

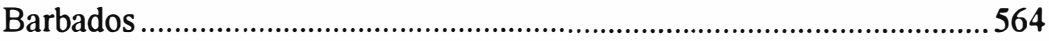

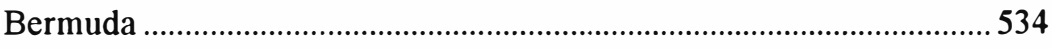

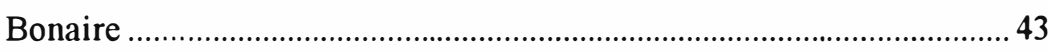

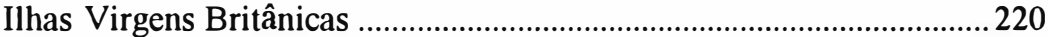

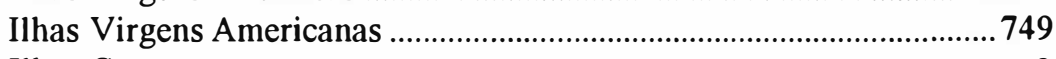

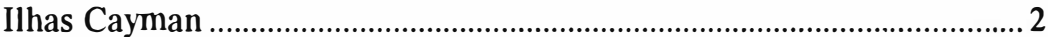




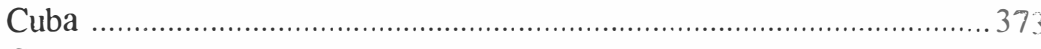

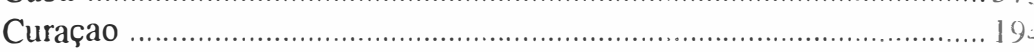

República Dominicana ............................................................ 1.39

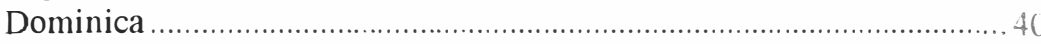

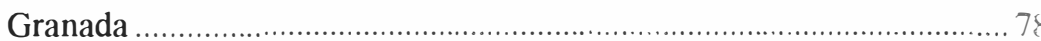

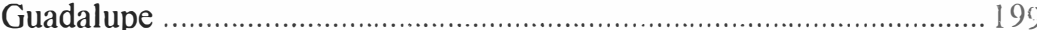

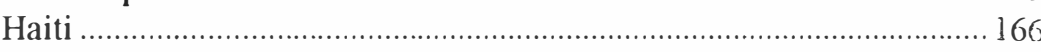

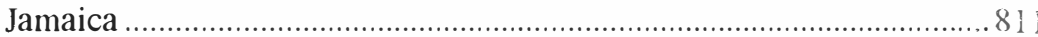

Martinica …

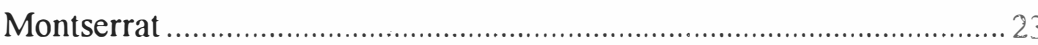

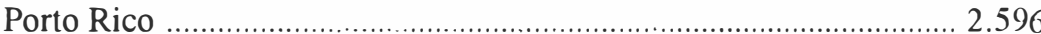

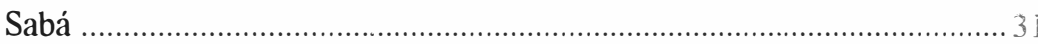

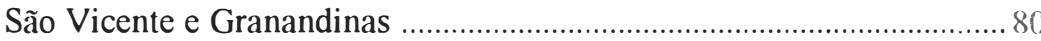

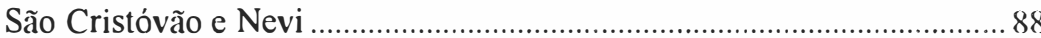

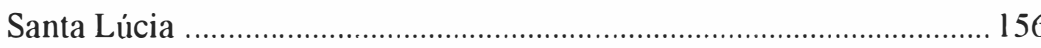

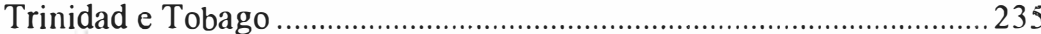

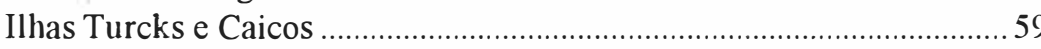

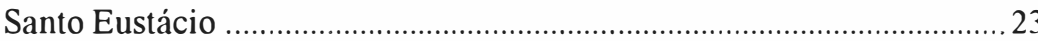

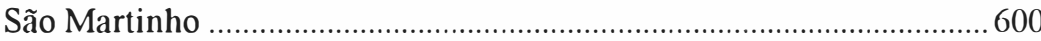

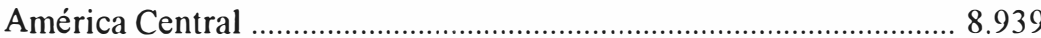

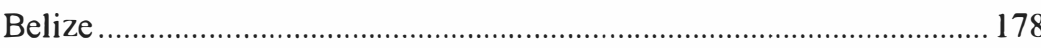

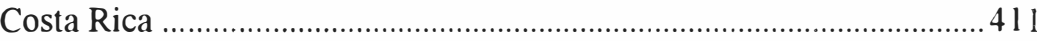

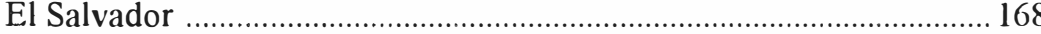

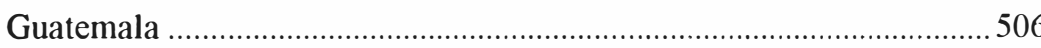

Honduras ……

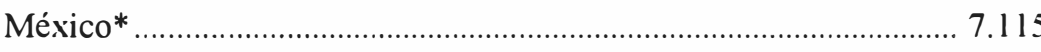

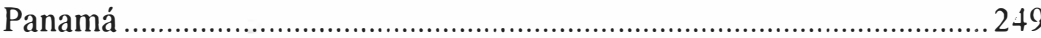

${ }^{*}$ ) - Méxicopertence geograficamente à América do Norte. Foi aqui incluído porcritériocultural

\section{DISCRIMINAÇÃO}

EM MILHÕES

América do Norte

61.710

Canadá

19.366

EUA

42.344

América do Sul ................................................................................ 9.998

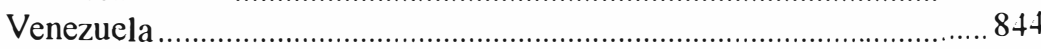

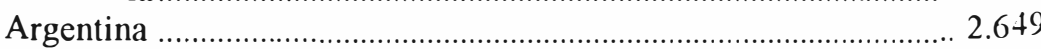

106

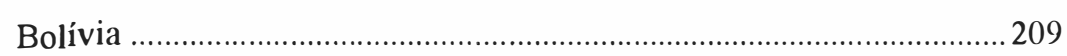

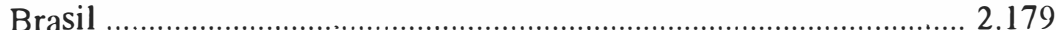

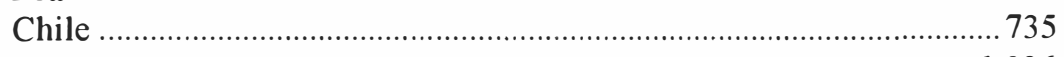

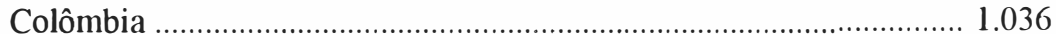

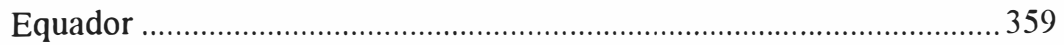

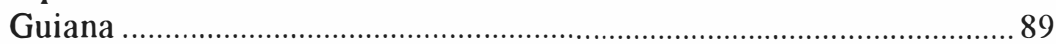

Paraguai

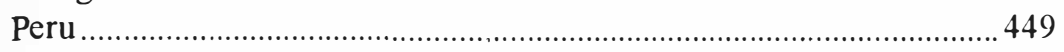

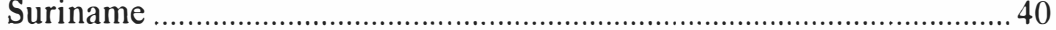

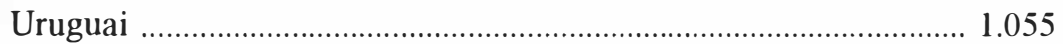

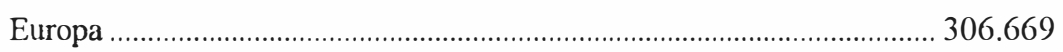

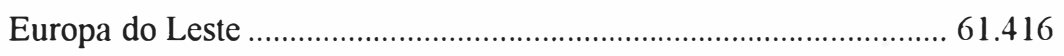

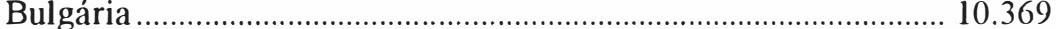

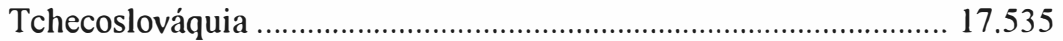

ex-Rep. Democrática Alemã ......................................................... 2.789

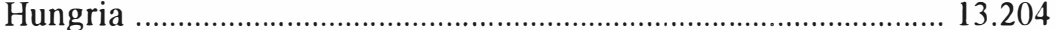

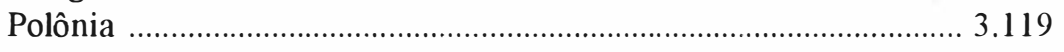

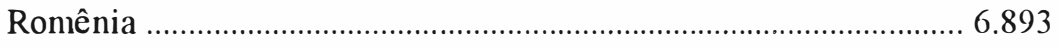

ex-URSS ..... 7.509

Europa do Norte ….................................................................... 29.369

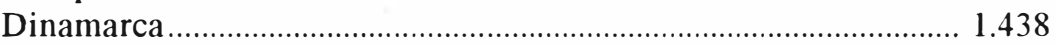

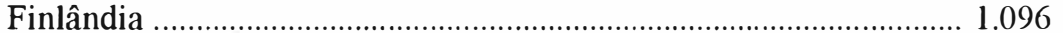

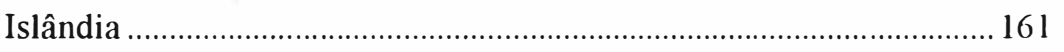

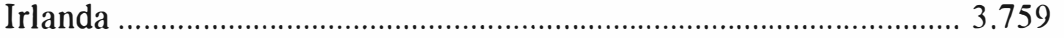

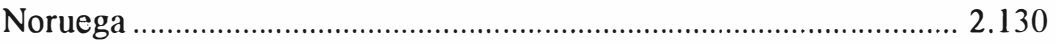

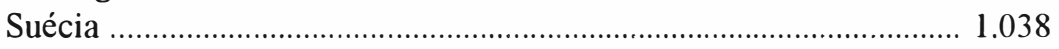

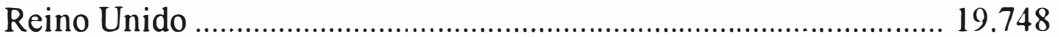

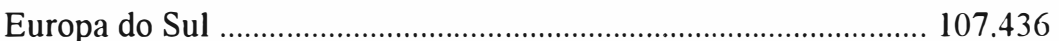

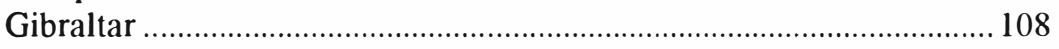

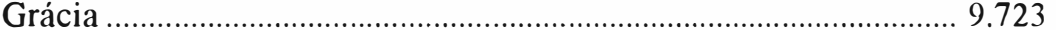

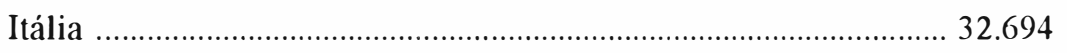

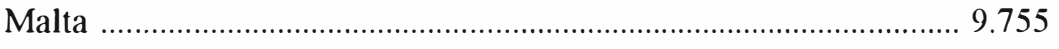

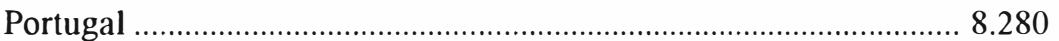

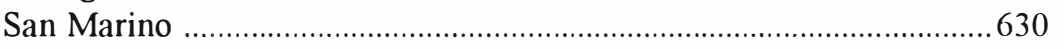

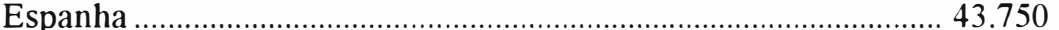

ex/Iugoslávia .............................................................................. 12.273

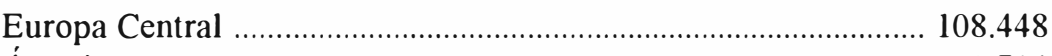

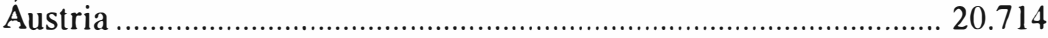

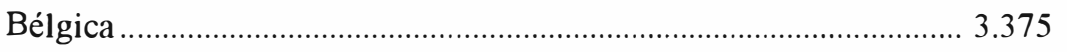




França ...
ex/Rep. Federal da Alemanha
Liechtenstein
Luxemburgo
Mônaco
Holanda

